\title{
IMPACT OF ACID SCARIFICATION AND COLD MIST STRATIFICATION ON ENHANCING SEED GERMINATION AND SEEDLING EARLY GROWTH OF Albizia lebbeck (L.) Benth.
}

Hivi Shawkat Ibrahim

Othman Kamil Aref Hawramee

Horticulture Department - College of Agricultural Sciences Engineering University of Sulaimani

Email:hivi.ibrahim@univsul.edu.iq

\begin{abstract}
The thick, hard and water-impermeable seed coat cause physical dormancy and low germination rate in Albizia lebbeck (L.), to overcome this physical dormancy, seeds were pretreated with concentrated $\mathrm{HCl}$ and cold mist condition. Immersing seeds in concentrated $\mathrm{HCl}$ acid $37 \%$ for 30 and $45 \mathrm{~min}$ effectively raised seed germination rate $(35.56 \%$ and $46.67 \%)$ respectively as compared to control treatment $(15.56 \%)$. Cold mist storage at $5^{\circ} \mathrm{C}$ for 4 and 8 weeks also significantly increased germination percentage $(51.11 \%$ and $68.89 \%)$ respectively. Furthermore, the combination of cold mist stratification for 8 weeks and immersion in $\mathrm{HCl}$ for $15 \mathrm{~min}$ boost the germination rate to $75.56 \%$ an increase of $59.90 \%$ comparing to control treatment. For seedling parameters, all treatments have positive effects on the studied characters highest seedling height $(37 \mathrm{~cm})$ and number of leaves per plant (18 leaves) where found in, 8 weeks cold mist condition, however, the combination of $15 \mathrm{~min}$ acid scarification and 8 week cold mist stratification resulted in higher leaves area (207.52). Acid scarification and cold mist stratification both increased germinations and improved seedling features, but germination rates were highest and fastest when these treatments were applied together. The results suggest that to enhance seedling qualities, seed germination rate and speed, a combination of scarification and stratification should be used.

Keywords: Albizia lebbeck, seeds, acid scarification, cold mist stratification.
\end{abstract}

Received:14/1/2019 Accepted: 3/9/2019

\section{INTRODUCTION}

Albizia lebbeck L. is a deciduous fast growing tree, attain an average maximum height of 8 to $15 \mathrm{~m}$, with a thin spread crown, native to tropical Asia, belongs to Mimosaceae family, the leaves are bipinnate, $7.5-15 \mathrm{~cm}$ long with 1 to 4 pairs of pinnae, each pinna with 6-18 leaflets. The flowers are very fragrant; it has a long flat and oblong seed pods, 3-12 seeds per pod, brown and flattened (Warrier, 2010). A. lebbeck (L.) multi-purpose tree has the ability to fix atmospheric nitrogen that improves the chemical structure of the soil, drought resistant, and provides shade (Faisal et al., 2012)

The tree has been suggested as an ornamental and plantation tree throughout the tropics (Parrotta, 2002), used in home gardens, parks and roadsides. It grows in a wide range of climates including an annual rainfall range of 600- $2500 \mathrm{~mm}$. However, it also grows successfully in areas with annual rainfall as low as $400 \mathrm{~mm}$. while the species is adapted to different soil types, from acid soils to alkaline and saline soils, the tree grows best on well-drained, moist soils (Prinsen, 1986). 
The seeds of this family have impermeable seed coat (Al-Menaie et al., 2010). The thick hard seed coat and impermeable to water caused to physical dormancy which due to irregular, slow germination and low germination rate (Nongrum and Kharlukhi, 2013; Jackson, 1994a; Baskin and Baskin,2004). Physical dormancy could be overcome through many ways, such as stratification at cold temperature storage that effectively break seed dormancy and enhance germination and increase its rate to more than $80 \%$ (Pipinis et al. 2009; Roh et al. 2004). As well as acid scarification treatment of species with hard seed coats is known to be highly effective in improving induce germination (Youssef, 2008; Kobmoo and Hellum, 1984).

This study aims to determine the effectiveness of acid ( $\mathrm{HCl})$ scarification and cold mist stratification on breaking down the dormancy and increasing germination rate of Albizia lebbeck (L.) tree seeds.

\section{Seed collection and processing}

\section{MATERIALS AND METHODS}

Mature pods were collected on November 2018 from low branches of Albizia lebbeck (L.) trees by hand, in the private garden at Sitak district located at elevation $1130 \mathrm{masl}$. (35 $38^{\circ} \mathrm{N}$ and $45^{\circ} 30^{\prime} \mathrm{E}$ ) about $25 \mathrm{~km}$ northeast of Sulaimani city. Then, seeds were extracted manually from the pods, after removing all abnormal seeds, the cleaned seeds packed in plastic bags and stored in a dark place at room temperature till sowing time.

\section{Experiment site}

The experiment was performed during the period $\left(20^{\text {th }}\right.$, February to the end of May) 2018 in the lath house of Horticulture Department, College of Agricultural Sciences, University of Sulaimani at Bakrajo district 10km Westside of Sulaimani city, which is located at elevation 743 masl. $\left(35^{\circ} 32 \mathrm{~N}\right.$ and $\left.45^{\circ} 21^{\prime} \mathrm{E}\right)$.

\section{Preparation of growing medium}

The growing medium was prepared by mixing peat moss and river sand with the proportion $(1: 1) \mathrm{V} / \mathrm{V}$, the growing medium was distributed to 540 plastic pots with $(6 \times 8) \mathrm{cm}$.

\section{Treatment and experimental design}

The experiment included study the effect of two factors on seed germination and seedling early growth.

The combination treatment comprised of two factors:

Factor 1: Acid scarification: Seeds were immersed in $\mathrm{HCl}$ concentrations $\% 37$ for 15, 30 and 45 minutes in addition to control (without immersion) in beakers, then the acid was discharged, and seeds were repeatedly rinsed in running tap water followed by distilled water until considered safe to handle. Then seeds were sown in plastic pots.

Factor 2: Cold mist stratification: Seeds were stored in plastic bags mixed with wet construction sand, closed tightly and stored for 4 and 8 weeks in a refrigerator at $5^{\circ} \mathrm{C}$, and monitored weekly to maintain the sand moist.

The treated seeds of each treatment were seeded in plastic pots $(6 \times 8) \mathrm{cm}$ filled with growing medium singly and in combination on $20^{\text {th }}$ February 2018. The 
experiment was applied as a factorial experiment according to randomized complete block design (RCBD) under lath house condition with total 12 combination treatments, each treatment was replicated three times, using 15 pots of each replication seeded by one seed.

The combination treatments were denoted as follows:

T1: Control (without treatments).

T2: Seeds immersed in $37 \%$ concentration of $\mathrm{HCl}$ acid for $15 \mathrm{~min}$.

T3: Seeds immersed in $37 \%$ concentration of $\mathrm{HCl}$ acid for $30 \mathrm{~min}$.

T4: Seeds immersed in $37 \%$ concentration of $\mathrm{HCl}$ acid for $45 \mathrm{~min}$.

T5: Cold mist storage at $5^{\circ} \mathrm{C}$ for 4 weeks.

T6: Cold mist storage at $5^{\circ} \mathrm{C}$ for 8 weeks.

T7: Cold mist storage at $5^{\circ} \mathrm{C}$ for 4 weeks with immersion in $37 \%$ concentration of $\mathrm{HCl}$ acid for $15 \mathrm{~min}$.

T8: Cold mist storage at $5^{\circ} \mathrm{C}$ for 4 weeks with immersion in $37 \%$ concentration of $\mathrm{HCl}$ acid for $30 \mathrm{~min}$.

T9: Cold mist storage at $5^{\circ} \mathrm{C}$ for 4 weeks with immersion in $37 \%$ concentration of $\mathrm{HCl}$ acid for $45 \mathrm{~min}$.

T10: Cold mist storage at $5^{\circ} \mathrm{C}$ for 8 weeks with immersion in $37 \%$ concentration of $\mathrm{HCl}$ acid for $15 \mathrm{~min}$.

T11: Cold mist storage at $5^{\circ} \mathrm{C}$ for 8 weeks with immersion in $37 \%$ concentration of $\mathrm{HCl}$ acid for $30 \mathrm{~min}$.

T12: Cold mist storage at $5^{\circ} \mathrm{C}$ for 8 weeks with immersion in $37 \%$ concentration of $\mathrm{HCl}$ acid for $45 \mathrm{~min}$.

During the experiment period, watering and weeding processing were performed regularly as needed. The germination process was monitored every day, and germinated seeds were counted for 12 weeks from appearing first germinated seed on $6^{\text {th }}$, March 2018 until the end of May 2018.

\section{Parameters measurement:}

At the end of experiment the following parameters were measured.

\section{1- Germination parameters:}

- Germination \%, calculated by using the following formula:

Germination $\%=$ Number of germinated seeds $/$ Total number of seeds $\times 100$ ISTA (1999).

- Speed of Emergence Index, and calculated by the following formula:

Speed of germination $=\mathrm{n} 1 / \mathrm{d} 1+\mathrm{n} 2 / \mathrm{d} 2+\mathrm{n} 3 / \mathrm{d} 3+----{ }_{---} \quad$ Czabator, F. J. (1962).

Where, $\mathrm{n}=$ number of germinated seeds, $\mathrm{d}=$ number of days.

- Time request for $50 \%$ of germinated seeds (days).

\section{2- Seedling Growth Parameters:}

Growth parameters such as shoot and taproot length, number of leaves and leave areas were measured at the end of May 2018. Shoot height $(\mathrm{cm})$ was measured by the ruler. Taproot length $(\mathrm{cm})$ also measured by the ruler. Leaves area $\left(\mathrm{cm}^{2}\right)$ measured by using (Digimizer image analysis) software program application (https:// www. digimizer.com/); downloaded on the personal computer, and based on image analysis by determining the dark spots at the images of the leaves.

\section{Statistical analysis:}


Data obtained were subjected to analysis of variance (ANOVA) by using XLSTAT 2016 data analysis software program (https://www.xlstat.com) with Duncan's Multiple Range Test (DMRT) $\mathrm{P} \leq 0.05$, to compare the differences between treatment means.

\section{1- Germination parameters (Table 1):}

\section{RESULTS}

Scarification by $\mathrm{HCl}$ acid and increasing immersion time from 0.0 minute (control) to 15, 30 and 45 minutes significantly increased germination percentage of Albizia lebbeck (L.) seeds from (15.56\%) to (26.67\%), (35.56\%) and (46.67\%) respectively.

Cold mist stratification of Albizia lebbeck (L.) seeds significantly increased germination percentage; from only $(15.56 \%)$, to $(51.11 \%)$ for cold mist stratification at $5^{\circ} \mathrm{C}$ for 4 weeks and most significantly in 8 weeks stratification $(68.89 \%)$,

The combination interaction effects of acid scarification and cold mist stratification revealed that treating seeds with cold mist stratification at $5^{\circ} \mathrm{C}$ for 8 weeks followed by acid scarification for 15 minutes delivered highest germination percentage $(75.56 \%)$ amongst all the treatments, also stratification at $5^{\circ} \mathrm{C}$ for 4 weeks followed by scarification for 15 and 30minutes resulted in (53.33\%) and 60\% germination respectively. Moreover, increasing emersion time in $\mathrm{HCl}$ acid to 30 and 45 minutes in stratification for 8 weeks, and immersing in concentrated $\mathrm{HCl}$ acid for 45 minuts and 4 weeks stratification; the germination percentage reduced to (51.11\%), (44.44\%) and (55.56\%).

The results also revealed that $\mathrm{HCl}$ scarification accelerates the speed of germination significantly and decrease the time (day) to $50 \%$ of seed germination of Albizia lebbeck (L.) from 84 days for the control to 70 days for immersed in $\mathrm{HCl}$ acid for 45 minutes. While the average of $50 \%$ of seed germination time varied to 55 and 50 days when stratified at $5^{\circ} \mathrm{C}$ for 4 and 8 weeks respectively. The shortest time was 49 days in which seeds stored 8 weeks at $5^{\circ} \mathrm{C}$ and followed by immersion in concentrated $\mathrm{HCl}$ acid for 15 minutes.

Table (1): Mean comparison of different treatments of $\mathrm{HCl}$ acid scarification, cold mist stratification and interaction between them on germination percentage, germination speed index and time to 50\% germination (day) of Albizia lebbeck (L.).

\begin{tabular}{|c|cc|c|c|}
\hline Treatments & Germination \% & $\begin{array}{c}\text { Germination } \\
\text { speed index }\end{array}$ & $\begin{array}{c}\text { Time to 50\% } \\
\text { germination (day) }\end{array}$ \\
\hline T1 & 15.56 & $\mathrm{~g}$ & 0.08 & 84 \\
\hline $\mathrm{T} 2$ & 26.67 & $\mathrm{fg}$ & 0.14 & 77 \\
\hline $\mathrm{T} 3$ & 35.56 & ef & 0.15 & 75 \\
\hline $\mathrm{T} 4$ & 46.67 & $\mathrm{de}$ & 0.19 & 70 \\
\hline $\mathrm{T} 5$ & 51.11 & $\mathrm{~cd}$ & 0.27 & 55 \\
\hline $\mathrm{T} 6$ & 68.89 & $\mathrm{ab}$ & 0.40 & 50 \\
\hline
\end{tabular}




\begin{tabular}{|c|cc|c|c|}
\hline $\mathrm{T} 7$ & $53.33 \quad \mathrm{~cd}$ & 0.29 & 63 \\
\hline $\mathrm{T} 8$ & $60.00 \mathrm{bc}$ & 0.30 & 54 \\
\hline $\mathrm{T} 9$ & $55.56 \quad \mathrm{~cd}$ & 0.35 & 56 \\
\hline $\mathrm{T} 10$ & $75.56 \quad \mathrm{a}$ & 0.44 & 49 \\
\hline $\mathrm{T} 11$ & $51.11 \mathrm{~cd}$ & 0.23 & 65 \\
\hline $\mathrm{T} 12$ & $44.44 \quad \mathrm{de}$ & 0.20 & 50 \\
\hline $\mathrm{Std}^{* *}$ & 3.259 & & \\
\hline
\end{tabular}

*Values followed by the same letter did not differ significantly $(\mathrm{P} \leq 0.05)$ according to Duncan's multiple range tests.

** Standard error of the mean.

\section{2- Seedling Growth Parameters:}

The effect of different exposure of scarification period and cold mist stratification significantly $(\mathrm{p} \leq 0.05)$ influenced the mean shoot length values of Albizia lebbeck (L.) Figure 1(a) the highest value was $22.00 \mathrm{~cm}$ from immersing seeds for 45 minutes in $37 \% \mathrm{HCl}$ which did not differ significantly with those treated for $30 \mathrm{~min}$. The lowest value $13.5 \mathrm{~cm}$ was for non-treated seeds (T1 control), and also there were no significant differences between the control and each of scarifying (T2) for 15minutes and acid scarification for 30min (T3).

Furthermore, Figure 1(b) shows that the significant influence of cold mist stratification on shoot height $(\mathrm{cm})$ and the results were 24.67 and $37.00 \mathrm{~cm}$ seedling height stratifying at $5^{\circ} \mathrm{C}$ for 4 weeks and 8 weeks. It can be concluded that immersion seeds in $37 \% \mathrm{HCl}$ for 15,30 and 45 minutes and also storage of seeds at $5^{\circ} \mathrm{C}$ for 4 or 8 weeks can improve and invigorate the germination of Albizia lebbeck (L.) tree seeds.
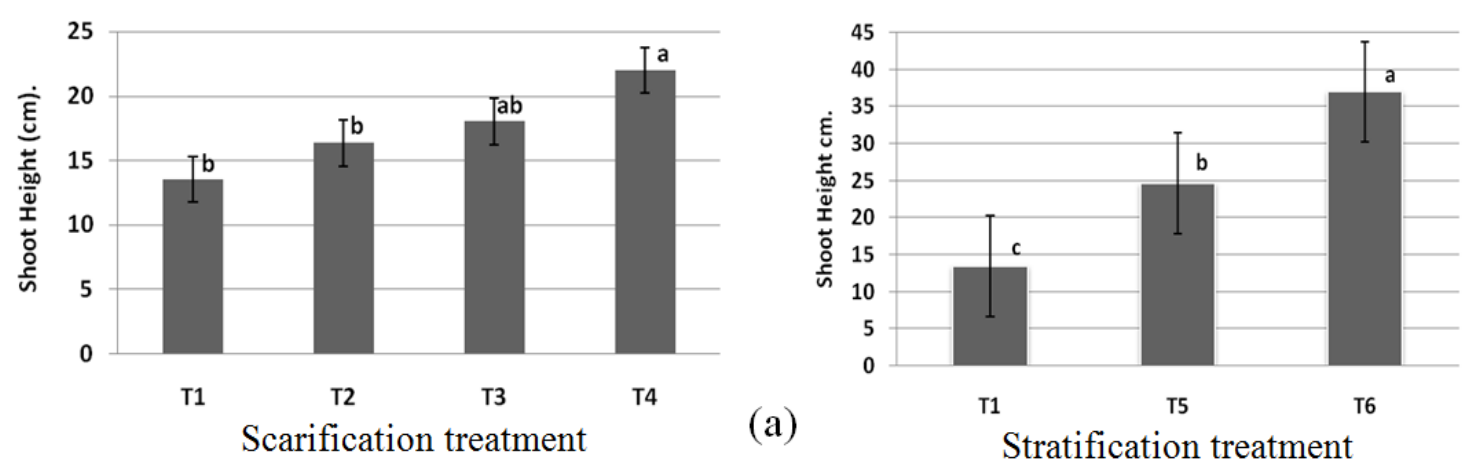

(b)

Figure (1): Effect of (a ) acid scarification and (b) cold mist stratification on shoot height $(\mathrm{cm})$ of Albizia lebbeck $(\mathrm{L}$.) seedling. Means not followed by the same letter differ significantly at $(\mathrm{P} \leq 0.05)$.

There were significant differences between acid scarification of $A$. lebbeck seeds, which immersion in $\mathrm{HCl}$ acid (37\%) for 30minutes enhance seedlings to tallest taproot $42.83 \mathrm{~cm}$, followed by $45 \mathrm{~min}(33.50 \mathrm{~cm}$.) and 20.50 for $15 \mathrm{~min}$ 
immersion as compared to $12.33 \mathrm{~cm}$ for control Figure 2(a). Cold mist storage at $5^{\circ} \mathrm{C}$ for 4 weeks and 8 weeks showed significant effects on taproot length $\mathrm{cm}$, which were 27.0, 23.00 and $12.33 \mathrm{~cm}$; for 4 weeks, 8 weeks and control respectively Figure 2(b).
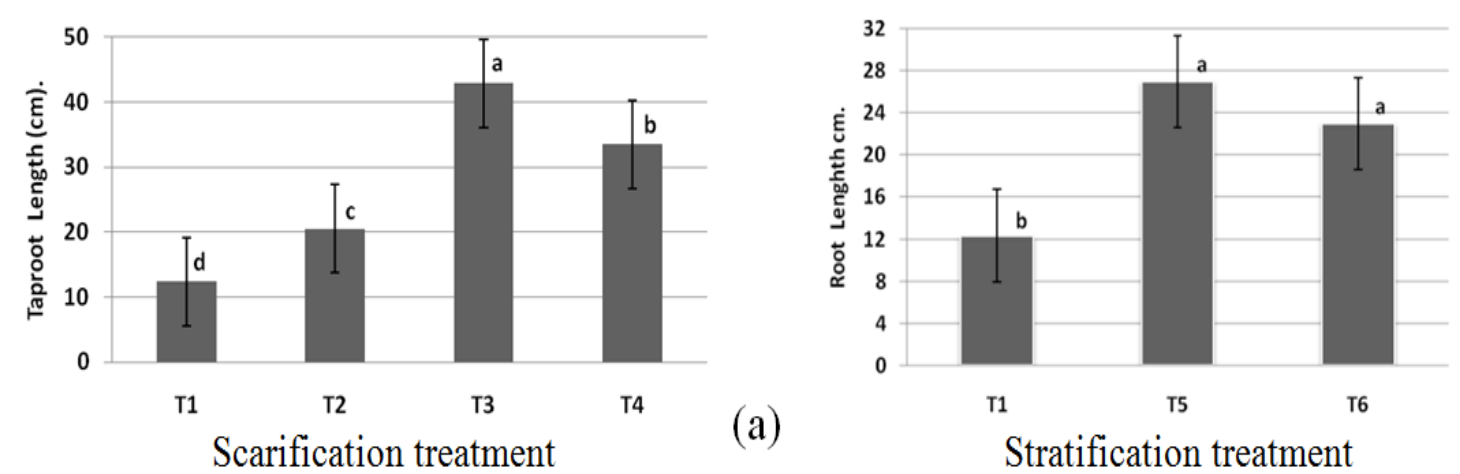

Figure (2): Effect of (a) acid scarification and (b) cold mist stratification on taproot length $(\mathrm{cm})$ of Albizia lebbeck (L.) seedling. Means not followed by the same letter differ significantly at $(\mathrm{P} \leq 0.05)$.

Results presented in Figure 3(a;b); suggest that there are no statistical differences between acid scarification durations and cold mist stratification duration, while all treatments significantly higher than non-treated seeds.
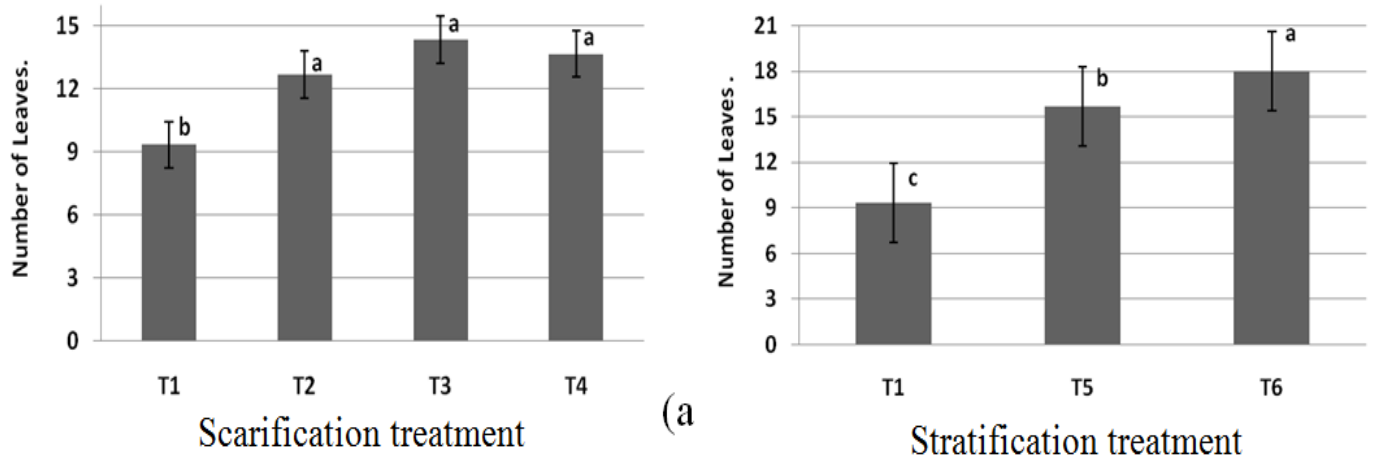

Figure (3): Effect of (a) acid scarification and (b) cold mist stratification on number of leaves of Albizia lebbeck (L.) seedling. Means not followed by the same letter differ significantly at $(\mathrm{P} \leq 0.05)$.

As presented in figure 4(a); scarified A. lebbeck seeds in $\mathrm{HCl}$ acid for 30 and $45 \mathrm{~min}$ significantly had more leave area than non-scarified seeds, the highest mean value were recorded $\left(113.44 \mathrm{~cm}^{2}\right)$ from seeds pretreated with $\mathrm{HCl}(37 \%)$ acid for $30 \mathrm{~min}$ followed by seedling originated from seeds immersed in $\mathrm{HCl}$ for $45 \mathrm{~min}$ $\left(61.62 \mathrm{~cm}^{2}\right)$, while the lowest mean leave area $\left(35.75 \mathrm{~cm}^{2}\right)$ obtained from untreated seeds but was not statistically different with $15 \mathrm{~min}$ acid immersion. Cold mist stratification gave significantly higher leaves areas over the control (T1), the results were $164.39 \mathrm{~cm}^{2}$ for cold mist storage at $5^{\circ} \mathrm{C}$ for 8 weeks and $51.61 \mathrm{~cm}^{2}$ for storage at same condition for 4 weeks Figure 4(b). 

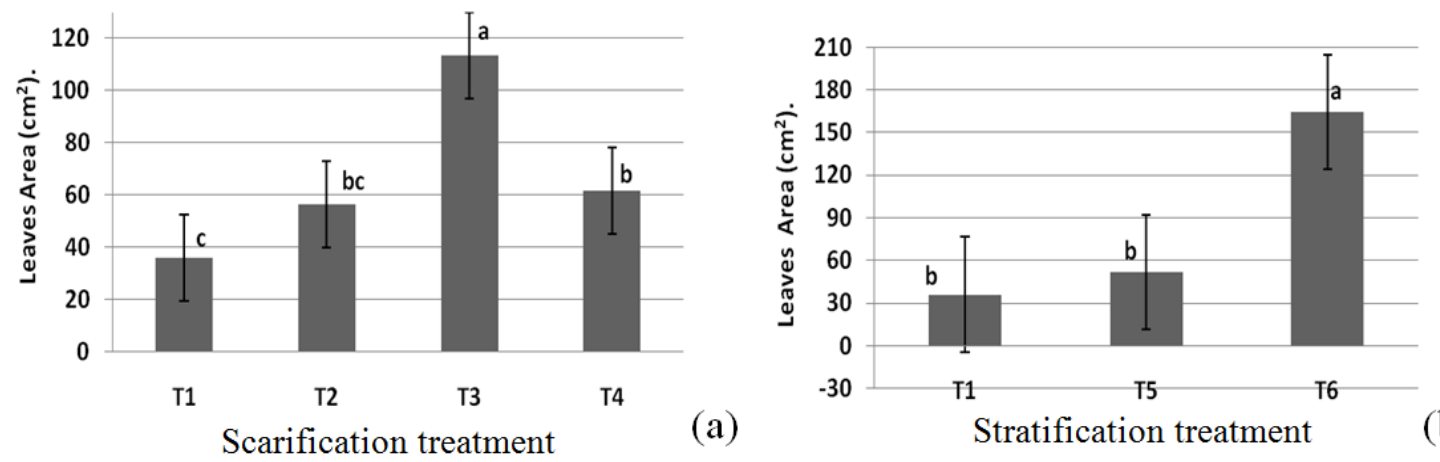

(a)

Stratification treatment

Figure (4): Effect of (a) acid scarification and (b) cold mist stratification on leaves area $\left(\mathrm{cm}^{2}\right)$ of Albizia lebbeck (L.) seedling. Means not followed by the same letter differ significantly at $(\mathrm{P} \leq 0.05)$.

Finally, Table 2 shows how interactions of $\mathrm{HCl}$ acid scarification and cold mist stratification effectively act on growth parameters of Albizia lebbeck (L.) seedlings. Results indicate that interaction of immersion in $37 \%$ concentration of $\mathrm{HCl}$ acid for $30 \mathrm{~min}$ and cold mist storage at $5{ }^{\circ} \mathrm{C}$ for 4 weeks (T8) superior in seedling height $(33.17 \mathrm{~cm})$, root lengths $(30.50 \mathrm{~cm})$, and number of leaves 19.00 , while (T10) interaction of immersion in $37 \%$ concentration of $\mathrm{HCl}$ acid for $15 \mathrm{~min}$ and cold mist storage at $5 \circ \mathrm{C}$ for 8 weeks, upper in seedling height $(34.33 \mathrm{~cm})$ and leaves area $\left(207.52 \mathrm{~cm}^{2}\right)$.

However, another interaction had a significant harmful impact on studied seedling characters in comparison to the other interactions the recorded values for (T12) were $20 \mathrm{~cm}, 15.5 \mathrm{~cm}, 9.67$ and $43.54 \mathrm{~cm}^{2}$ for each of shoot height, root lengths, number of leaves and leaves area respectively.

Table (2): Interaction effect of $\mathrm{HCl}$ acid scarification and cold mist stratification on shoot height $(\mathrm{cm})$, taproot lengths $(\mathrm{cm})$, number of leaves and leaves area $\left(\mathrm{cm}^{2}\right)$ of Albizia lebbeck (L.).

\begin{tabular}{|c|c|c|c|c|c|c|}
\hline Treatments & $\begin{array}{c}\text { Shoot Height } \\
\mathrm{cm} .\end{array}$ & $\begin{array}{l}\text { Root Length } \\
\mathrm{cm} .\end{array}$ & $\begin{array}{l}\text { No. of } \\
\text { Leaves }\end{array}$ & & $\begin{array}{r}\text { Leaves A } \\
\mathrm{cm}^{2}\end{array}$ & \\
\hline $\mathrm{T} 1$ & $13.50 \quad d$ & $12.33 \mathrm{f}$ & 9.33 & $\mathrm{e}$ & 35.75 & d \\
\hline $\mathrm{T} 7$ & 24.17 & $23.50 \quad b$ & $16.33 \mathrm{l}$ & $b c$ & 118.73 & c \\
\hline T8 & 33.17 & $30.50 \mathrm{a}$ & 19.00 & $\mathrm{a}$ & 162.56 & $\mathrm{~b}$ \\
\hline T9 & 29.00 & $19.00 \mathrm{~d}$ & 15.33 & $\mathrm{c}$ & 53.61 & d \\
\hline $\mathrm{T} 10$ & 34.33 & $21.50 \mathrm{c}$ & 16.67 & b & 207.52 & $\mathrm{a}$ \\
\hline T11 & $25.50 \quad b c$ & $19.50 \mathrm{~d}$ & 13.00 & d & 47.7 & $\mathrm{~d}$ \\
\hline T12 & 20.00 & $15.50 \mathrm{e}$ & 9.67 & $\mathrm{e}$ & 43.54 & $\mathrm{~d}$ \\
\hline Std** & 2.060 & 0.500 & 0.380 & & 8.721 & \\
\hline
\end{tabular}

* Mean values in a column followed by the same letter did not differ significantly $(\mathrm{P} \leq 0.05)$ according to Duncan's multiple range tests.

** Standard error of the means. 


\section{DISCUSSION}

\section{1- Germination parameters:}

Scarified seeds of Albizia lebbeck (L.) by $\mathrm{HCl}$ acid, and increasing immersion time to $45 \mathrm{~min}$ significantly increased germination percentage to $46.67 \%$. This increasing of germination rate also has been reported by other researchers (Abubakar and Maimuna, 2013; Babashpour and Sharifivash, 2010; Noorafkan and Khoshkhui, 2005; Gizachew and Scarisbrick, 1999). The effect of concentrated HCl on stimulation of seed germination might be due to that the acid may soften hard seed coats and allowing easier water uptake and oxygen diffusion resulting in enzymatic hydrolysis and hence transforming the embryo into a seedling (Olatunji et al., 2012; Alamgir and Hossain, 2005).

Cold mist stratification of Albizia lebbeck (L.) seeds also significantly increased germination percentage $68.89 \%$; the results reported in this study agreed with those in literature (Gebre and Karam, 2004; Agrawal, 1995; Hartmann et al., 1997), in which that stratification is necessary after embryo development when seed dormancy due to embryo factor.

The combination interaction effects of acid scarification and cold mist stratification revealed that treating seeds with cold mist stratification at $5^{\circ} \mathrm{C}$ followed by acid scarification delivered high germination percentage $75.56 \%$; this might be due to that scarification and stratification together soften the hard seed coat which leads to allowing greater water absorption, gaseous exchange and finally enhances germination significantly. The previous data is in agreement with reports of Liu et al. (1981); Jones and Geneva (1995); Hamilton and Carpenter (1975), who worked on seeds of Cercis spp. Also, Harrie and Erick (1998) have reported that scarification or stratification of Acacia senegal (L.) seeds before sowing would produce the best germination result. Seeds could not sustain the shock of longtime immersion in concentrated $\mathrm{HCl}$ acid that may cause damage to the embryo and as at the results significantly decreased germination percentage to $44.44 \%$.

Accelerating germination from 84 days to 70 days and decreasing the time (day) to $50 \%$ of seed germination of Albizia lebbeck (L.) seeds treated with $\mathrm{HCl}$ acid; while the average of $50 \%$ of seed germination time varied when stratified period at $5^{\circ} \mathrm{C}$ differed, this indicates that impermeability and hardness of seed coat is the primary inhibitor of germination and the accelerate of germination and permits radical emergence might be due to absorbing more water after weakening seed coat structure. Where seed coat is softened, the process of hydrolysis could commence releasing simple sugars that could be readily utilized in protein synthesis, also releasing hormones such as auxins and ethylene could increase nucleic acid metabolism and protein synthesis (Irwin, 1982; Jackson, 1994b). HCL modified the seed coat that enhanced the germination process. It is evident from the present study that for optimum seed germination of $A$. senegal, the concentration of the acid should not exceed 50\% (Harrie and Erick, 1998). Completion of pregermination metabolic activities making the seed ready for soon germination compared with untreated seeds. Therefore, the rapid germination rate that was observed due to faster water uptake and earlier initiation of metabolism processes (Sedghi et al., 2010; Eskandari and Kazemi, 2011). 


\section{2- Seedling Growth Parameters:}

The effect of different exposure of scarification period and cold mist stratification significantly $(\mathrm{p} \leq 0.05)$ influenced the means of all seedling growth parameters values; shoot length, root length, number of leaves and leaves area of Albizia lebbeck (L.).

Increased seedling height also was reported by Thanuja et al., (2018) in Pterocarpus marsupium Roxb. Adequate growth of seedlings is dependent on the ease of seed germination and thus increasing the growth potential of seedlings and improving seedling competitiveness in a shorter time compared with non-treated seeds. On the other hand, untreated seeds (control) also germinated but it took a very long period after sowing which gave a germination percentage lower and shorter height of the seedling as compared to those scarified with acid and stratified at $5^{\circ} \mathrm{C}$.

Scarifying the seeds in concentrated hydrochloric acid increased imbibitions, and improved germination, seedling establishment and growth characteristics such as shoot and root length.

It can be concluded that the seedling growth rate and biomass accumulation such as leaves area $\mathrm{cm}^{2}$ is dependent on the ease of seed germination.

Treatments might have softened the seed coat of very accelerating infiltration of possible enzyme activity in the endosperm. A general assessment of the results of different scarification and stratification treatments demonstrated that they affect on the early growth stages of $A$. lebbeck seedlings wholly.

The exposure to acid was observed to cause the complete elimination of the integument, which possibly damaged the embryo and, as a consequence, the growth rate of different parts of the seedlings decreased, which agreed with a study by Sanabria et al., (2004) on seeds of Cratylia argentea; that reported the seed immersion in acid did not improve germination rate with regards to the control, caused increasing a high percentage of the death. In the present study, the effect of $\mathrm{HCl}$ scarification and stratification at $5^{\circ} \mathrm{C}$ was minimal in breaking the seed coat as is reflected in poor seedling emergence and other growth parameters. Longer exposure of the seeds to $\mathrm{HCl}$ might have damaged the embryo. Similar views have been expressed by Aduradola \& Adejomo (2005) for Erythrophleum suaveolens seeds. However, other factors such as the relative position of the seed on the parent plant, micro-environment, quantity of reserve food content and provenance seen in many species could be affecting on the variation in the timing, germination percentage of the seeds and also on initial growth parameters. (Gutterman, 1982; Gray \& Thomas, 1982; Owoh et al., 2011).

\section{CONCLUSIONS}

To overcome the physical dormancy with obtaining best seedling growth parameters, seeds pretreated with $37 \%$ concentrated of $\mathrm{HCl}$ for different immersion time and cold mist storage for 4 and 8 weeks at $5^{\circ} \mathrm{C}$ the study found that the best pretreatment was obtained by immersion seeds in $37 \%$ concentration of $\mathrm{HCl}$ acid for $30 \mathrm{~min}$. for all growth parameters; cold mist storage at $5^{\circ} \mathrm{C}$ for 8 weeks for best germination percentage, shoot height $(\mathrm{cm})$, number of leaves and leaves area $\left(\mathrm{cm}^{2}\right)$ 
and interaction effect of cold mist storage at $5^{\circ} \mathrm{C}$ for 8 weeks with immersion in $37 \%$ concentration of $\mathrm{HCl}$ acid for $15 \mathrm{~min}$ for all germination parameters, shoot height $(\mathrm{cm})$ and leaves area $\left(\mathrm{cm}^{2}\right)$.

تأثير التخديش بالحامض والتضيد البارد الرطب على تحسين إنبات البذور والنمو المبكر لثتلات الالبيزيا ALBIZIA LEBBECK (L.)

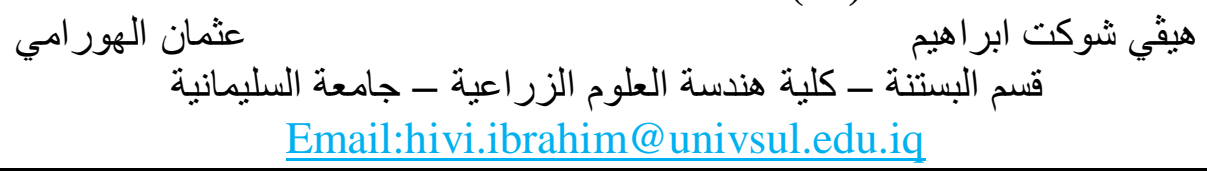

\section{الخلاصة}

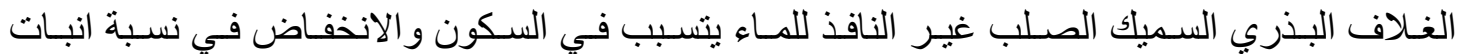

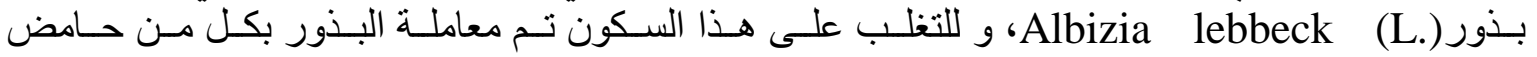

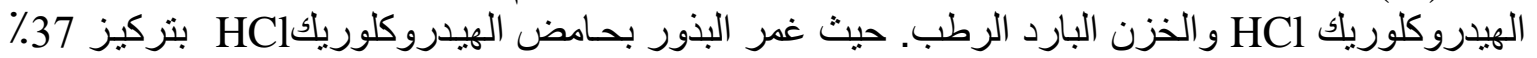

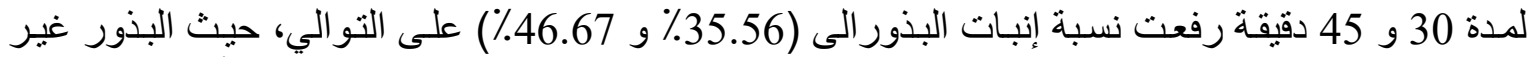

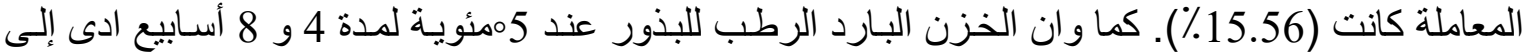

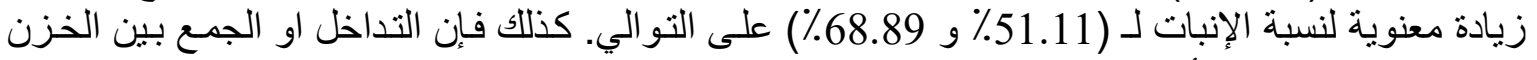

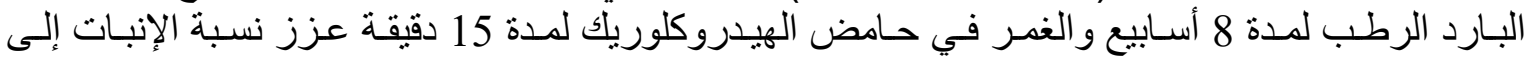

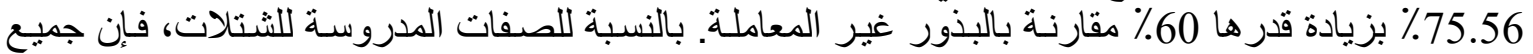

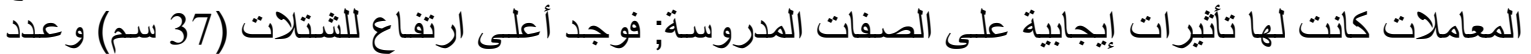

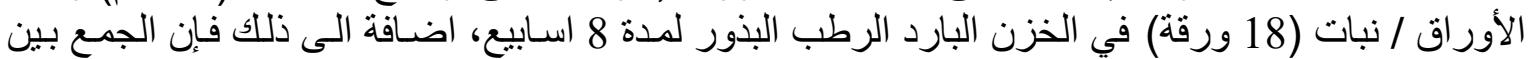

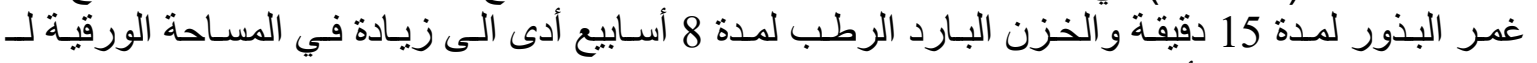

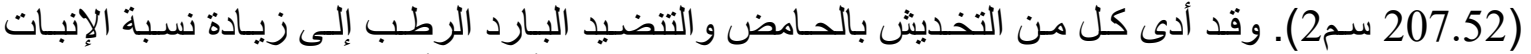

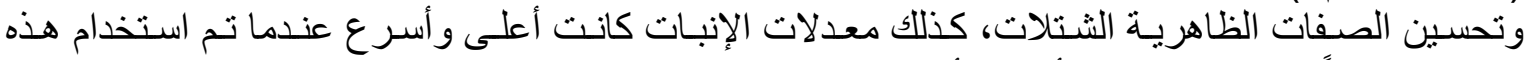

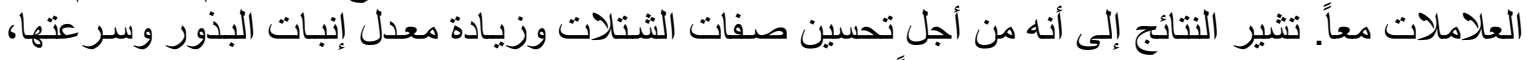

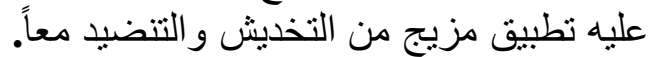

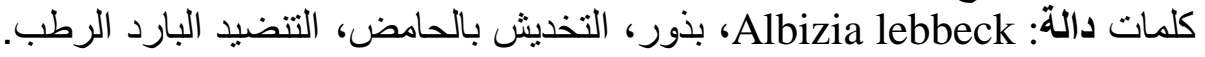

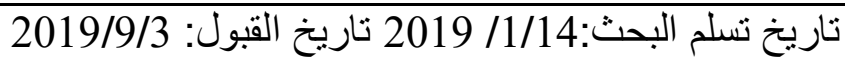

\section{REFERENCES}

Abubakar, Z. and A. Maimuna (2013). Effect of hydrochloric acid, mechanical scarification, wet heat treatment on germination of seed of Parkia biglobosa African Locust Bean (Daurawa) case study of gombe local government area. Journal of Applied Sciences and Environmental Management 17(1): 119-123.

Aduradola A.M. and A. Adejomo (2005). The Effect of Some Pretreatments on Germination of Seeds of Erythrophleum suaveolens. Proceedings of the $30^{\text {th }}$ Annual Conference of FAN, Kaduna held on 7 November, 2005, Kaduna, Kaduna, Nigeria, pp: 485-489.

Agrawal, P.K. (1995). Seed Dormancy. In: Techniques in Seed Science and Technology, (eds. P.K. Agrawal and M. Dadlani), second edition, South Asian Publishers Limited, India pp. 109-113.

Alamgir, M. and M.K. Hossain (2005). Effect of pre-sowing treatments on germination and initial seedling development of Albizia saman in the nursery. Journal of Forestry Research 16(3), 200-204. 
Al-Menaie, H.S.; O. Al-Ragam; A. Al-Shatti; M. Mathew and N. Suresh (2010). The effects of different treatments on seed germination of the Cassia fistula $\mathrm{L}$. and Cassia nodosa Buch.-Ham. Ex Roxb. in Kuwait. African Journal of Agricultural Research 5(3):230-235.

Babashpour, M. and R. Sharifivash (2010). Effect of acid scarification and hot water on seed germination of honey locust (Gleditschia triacanthos). Proceedings of the Fifth National Conference on New Ideas in agriculture. 2728 Bahman, Islamic Azad University (Isfahan).

Baskin, J.M. and C.C. Baskin (2004). A classification system for seed dormancy, Seed Science Research vol.14(1), pp.1-16.

Czabator, F.J. (1962). Germination value: An index combining speed and completeness of pine seed germination. Forest Science 8(4): 386 - 395.

Eskandari, H. and K. Kazemi (2011). Effect of Seed Priming on Germination Properties and Seedling Establishment of Cowpea (Vigna sinensis). Notulae Scientia Biologicae 3(4): 113-116.

Faisal, M.; P.P. Singh and R. Irchhaiya (2012). Review on Albizia lebbeck a potent herbal drug. International Journal of Pharmaceutics 3(5): 63-68.

Gebre, G.H. and N.S. Karam (2004). Germination of Cercis siliquastrum seeds in response to gibberellic acid and stratification. Seed Science and Technology 32(1):255-260.

Gizachew, L. and D. Scarisbrick (1999). Germination of Chamaecytisus palmensis as affected by ageing and method of pre-germination treatment. African Crop Science Journal 7(2): 165-171.

Gray D. and Thomas TH. (1982). Seed Germination and Seedling Emergence as Influenced by the Position of the Development of the Seed on, and Chemical Applications to, the Parent Plant. In: Khan A.A. (Ed.). The Physiology and Biochemistry of Seed Development, Dormancy and Germination, Elsevier Biomedical Press, New York. pp: 81-110.

Gutterman Y. (1982). Phenotypic Maternal Effect of Photoperiod on Seed Germination. In: Khan A.A. (Ed.). The Physiology and Biochemistry of Seed Development, Dormancy and Germination, Elsevier Biomedical Press, New York. pp: 67-79.

Hamilton, D.F. and P.L. Carpenter (1975). Regulation of seed dormancy in Elaeagnus angustifolia by endogenous growth substances. Canadian Journal of Botany 54(10):1068-1073.

Harrie, P.P. and F. Erick (1998). Propagating and Planting Trees. Agrodok Series; Hartman, H.T.; D.E. Kester and F.T. Davies (1990). Plant propagation principles and practices. $5^{\text {th }}$ ed. Reagents Prentice Hall, Inc. Eaglewood Cliff. New Jersey.

Hartmann, H.T.; D.E. Kester; F.T. Davies and R.L. Geneve (1997). Plant Propagation: Principles and Practices. Sixth edition. Prentice Hall, New Jersey, USA.

https://www.digimizer.com/download.php

https://www.xlstat.com/en/download 
International Seed Testing Association (ISTA) (1999). International rules for seed testing. Seed Science and Technology 27:333.

Jrwin, P.T. (1982). Plant Physiology. Addison-Wesley Pub. Co. Inc. U.S.A., pp. 501-540.

Jackson, J.K. (1994a). Manual of Afforestation in Nepal. Forest Research and Survey Center. $2^{\text {nd }}$ edition: pp. 718-724

Jackson, M.B. (1994b). Root-to-shoot communication in flooded plants. Involvement of Abscisic acid, ethylene and 1-aminocy clopropane-1carboxylic acid. Agronomy Journal 86(5): 775-781.

Jones, R.O. and R.L. Geneve (1995). Seed coat structure related to germination in eastern redbud (Cercis canadensis L.). Journal of the American Society for Horticultural Science 120(1):123-127.

Kobmoo, B. and A.K. Hellum (1984). Hot water and acid improve the germination of Cassia siamea Britt. seeds. The Embryon 1(1): 27-33.

Leck, M.A.; R.L. Simpson and V.T. Parker (2008). Chapter 1: Part I, Introduction, Why seedlings? In: Seedling Ecology Evolution. Leck, M.A.; Parker, V.T. and Simpson, R.L. (editors).

Liu, N.Y.; H. Khatamian and T.A. Fretz (1981). Seed coat structure of three woody legume species after chemical and physical treatments to increase seed germination. Journal of the American Society for Horticultural Science 106(5):691-694.

Nongrum, A. and L. Kharlukhi (2013). Effect of seed treatment for laboratory germination of Albizia chinensis. Journal of Forestry Research 24(4):709-713.

Noorafkan, H. and M. Khoshkhui (2005). Investigations on sexual propagation of golden rain (Koelreuteria paniculata laxm.) and chinese rain ( $k$. elegans seem.) trees. Journal of Horticultural Science and Technology 6 (2): 98-89.

Olatunji, D.; J.O. Maku and O.P. Odumefun (2012). Effect of pre-treatments on the germination and early seedlings growth of Acacia auriculiformis Cunn. Ex. Benth. African journal of plant science 6(14): 364-369.

Owoh P.W., M.O. Offiong, S.I. Udofia, V.U. Ekanem (2011) Effects of seed size on germination and early morphological and physiological characteristics of Gmelina arborea, Roxb. African Research Review 5: 422-433.

Parrotta, J.A. (2002). Albizia lebbeck (L.). In: Tropical Tree Seed Manual. Agriculture Handbook Number 721. Washington, DC, United States Department of Agriculture, Forest Service. pp. 274-276.

Pipinis, E.; E. Milios; M. Aslanidou; O. Mavrokordopoulou and P. Smiris (2009). The effect of stratification on seed germination of Jasminus fruticans L. (Oleaceae). A contribution to a better insight on the species germination ecology. International Journal of Botany 5(2): 181-185.

Prinsen, J.H. (1986). Potential of Albizia lebbeck (Mimosaceae) as a tropical fodder tree-a review of literature. Troical Grasslands 20(2):78-83.

Roh, M.S.; J.A. Bentz; P. Wang; E. Li and M. Koshioka (2004). Maturity and temperature stratification affect the germination of Styrax japonicus seeds. The Journal of Horticultural Science and Biotechnology 79(4): 645-651. 
Sanabria, D.; S.A. Ramón; O. Miguel and M. Ursulino (2004). Germination of arbustive forage leguminous seed of Cratylia argentea and Cassia moschata under different times of immersion in concentrated sulfuric acid. Bioagro 16 (3):225 (Abstract).

Sedghi, M.; Ali A. Nemati and B. Esmaielpou (2010). Effect of seed priming on germination and seedling growth of two medicinal plants under salinity. Emirates Journal of Food and Agriculture 22 (2), 130-139.

Thanuja, P.C.; Sadashiv Nadukeri; Shashikala Kolakar; M. Hanumanthappa; M. Ganapathi and K.L. Vasudev (2018). Enhancement of germination and seedling growth attributes of a medicinal tree species Pterocarpus marsupium Roxb. through pre sowing seed treatments. Journal of Pharmacognosy and Phytochemistry SP3: 165-169.

Warrier, C.S. (2010). Albizia lebbeck (L.) Benth. In: Manual of Economically important Forestry Species in South India, Institute of Forest Genetics and Tree Breeding (Indian Council of Forestry Research and Education), pp.79-91.

Youssef, A.M. (2008). Adaptive responses of some desert plants from different ecosystems of Suez road, Egypt. Research Journal of Agriculture and Biological Sciences 4(5): 595-603. 